\title{
Analysis of Survival Rates of Patients Diagnosed With Incipient Esophagic Cancer
}

\author{
Edmundo Carvalho Mauad, d, Maria do Rosario Dias de Oliveira Latorre ${ }^{\mathrm{a}}$, Thiago Buosi Silva ${ }^{\mathrm{a}}$, \\ Ricardo Mauad Daher ${ }^{a}$, Vinicius de Lima Vazquez ${ }^{\text {a }}$, Antonio Talvane Torres Oliveira ${ }^{a}$, \\ Adhemar Longatto Filho ${ }^{\mathrm{b}, \mathrm{c}}$
}

\begin{abstract}
Background: Esophagic cancer incidence is extremely variable worldwide. Also, the global survival rate has not oscillated significantly since last decade. Most of the worse prognoses are found among patients with advanced stages. Despite that, around $10 \%$ of cases occur in patients with initial stage, which strongly associate these patients with unfavorable prognosis. We sought to analyze the impact of time free of disease and global survival rates of patients with initial stage of esophagic cancer.
\end{abstract}

Methods: We studied 18 patients with initial stage of esophagic cancer (stage 0 and I), examined and treated at Hospital de Cancer de Barretos between 1990 and 2005.

Results: The vast majority of patients were male (83.3\%) with age up to 49 yarest old (77.8\%), squamous cell carcinoma (SCC) $(88.9 \%)$ and stage I $(83.3 \%)$. Most of them were smoker $(60.0 \%)$ and etilist $(62.5 \%)$. There were $38.9 \%$ of the patients with comorbities like dysphagia and epigastralgia correlated to other pathological conditions. We found free disease rates of $100 \%$ and $82.5 \%$, respectively for 12 and 36 months. The significant prognostic evidence was the age, epigastralgia symptoms and chemotherapy. From 18 patients, 6 passed away during the period of 36 months follow up due to cancer consequences. The probabilities of global survival were $76.7 \%$ and $64.4 \%$ after 12 and 36 months, respectively, and none of the analyzed variables influenced in theses rates.

Conclusions: Our data ratifies those from previous reported. The

\footnotetext{
Manuscript accepted for publication February 19, 2010

${ }^{a}$ Barretos Cancer Hospital, Department of Cancer Screening, Sao Paulo, Brazil

${ }^{\mathrm{b}}$ Laboratory of Medical Investigation (LIM) 14 of Department of Pa thology of Medical School of Sao Paulo University, Sao Paulo, Brazil

${ }^{c}$ Life and Health Sciences Research Institute (ICVS), School of Health Sciences, University of Minho, Braga, Portugal

${ }^{\mathrm{d} C}$ Corresponding author: Barretos Cancer Hospital, Rua Antenor Duarte Villella, 1331, Bairro Dr. Paulo Prata. Zip Code: 14784-400, Barretos, SP, Brazil. Email: prevencao@hcancerbarretos.com.br
}

doi:10.4021/wjon2010.02.193w global survival rates were worse than reported by literature, maybe in consequence of the poor clinical condition of many patients which limited the option for more aggressive therapy.

Keywords: Cancer survival rate; Insipient esophageal cancer; Esophagectomy; Cancer treatment

\section{Introduction}

Esophagic cancer incidence is extremely variable worldwide. In Europe, this type of cancer is uncommon, and the global survival rate has not oscillated significantly since last decade. The survival rates after five years fluctuate around $3 \%$ (for men in Slovenia or Italy) and 19\% (for women in Finland) [1]. New 16,470 esophagic cancer cases are estimated in United States for 2008 and the number of deaths around to 14,200 [2]. Brazil usually have inferior rates of esophagic cancer, but in the Center-south region the incidence is 15 new cases for 100,000 men, and four new cases for 100,000 women [3].

Esophagic carcinomas are commonly detected in advanced stage when more than $75 \%$ of esophagic space is blocked by the tumor. Consequently, dysphagia and pronounced weight losing are the principal symptoms observed in these patients $[4,5]$. The concomitant consumptions of alcohol and tobacco are significantly associated to the esophagic carcinogenesis [6].

Endoscopy screening is indicating to identify incipient lesions of esophagic tumor favoring more efficient treatment and best prognostic outcome. Japan studies demonstrated that screening endoscopic program detected almost $30 \%$ of esophagic carcinoma staged I and II in asymptomatic individuals $[7,8]$. Until 10 years ago, only $10 \%$ of all esophagic cancer was clinical stages (CS) 0 or 1 . But this percentage has been increasing in the recent years. Important data emerged from implement screening programs to detect incipient forms of esophagic cancer. In United States, the global survival rates in five years increased from $6 \%$ in 1975 to $11 \%$ and $18 \%$ in 1984 and 2003, respectively. Data from EUROCARE have showed that survival rates in Eu- 
rope is $33 \%$ after one year and $10 \%$ in 5 years with significant variation among different countries, additionally, it was demonstrated that there was no significant modification in the survival rates in two different periods: 1978 to 1980 and 1987 to1989 [9].

Importantly, patients with esophagic cancer detected in initial stages show survive rates of $88 \%$ after three years in German patients, $45 \%$ after 12 months in Iran, 67\% in five years in Japan and $78.3 \%$ in Korea. Considering all stages of esophageal cancer from Singapore, no significant variations have been observed in mortality rates since the 70's [10].

Most of the recurrence events are associated to the site of lesion development, type of the surgery used to remove the tumor, and multifocal lesions $[11,12]$. Histological type of the tumor is also an important prognostic parameter [13]. Despite the importance of this tumor, Latin American data regarding outcome is not available. Most of the strategies to reduce mortality consequent to the esophageal cancer could be cost-effectively improved if endoscopic investigation in high risk population was rationally considered. A number of initial lesions could be identified and the therapeutic procedures are more efficient.

The objective of this study was to evaluate associated factors related with esophageal incipient cancer examined at Barretos Cancer Hospital (HCB) - Pio XII Foundation, between 1990 and 2005.

\section{Patients and Methods}

The files of 1,853 esophageal cancer patients examined and treated in Barretos Cancer Hospital between 1990 and 2005 were revised. From these cases, $18(1.0 \%)$ were categorized as Stage 0 and I (TNM classification). Histopathological classification of these tumors considered initial esophageal cancer cases of in situ carcinoma and those cases with mucosal and submucosal, but without lymph node invasion.

Surgical procedures comprised transhiatal and transthoracic esophagectomy, followed by peritumoral lymphadenectomy, and radiotherapy and or chemotherapy if necessary.

The following variables were analyzed, (1) socio-demographic: gender, ethnicity, age, schooling level, alcoholism and smoking status; (2) clinical: symptomatology, time relapsed since the first symptoms, Body Mass Index (BMI) and comorbidity; (3) pathological: second primary tumor, histological type, lesion size, and stage; (4) therapeutics: surgery, radiotherapy, chemotherapy; (5) follow up: dates of recurrence, death and last clinical visit.

\section{Statistical evaluation}

Clinical and pathological data were stored and analyzed using the SPSS statistical software (version 16.0, SPSS Inc,
Chicago, IL, USA). Free disease interval and global survival rates were calculated after intervals of 12 and 36 months using Kaplan-Meier and log rank test curves for data comparison.

\section{Results}

Table 1 depicted the socio-demographic characteristics of the patients. The vast majority of the patients were men (15 cases, $83.3 \%$ ) with age up to 49 years old (14 cases, $77.8 \%$ ), had stage I (15 cases, $81.8 \%$ ) and squamous cell carcinoma (16 cases, $88.9 \%$ ). The majority of patients were alcoholic beverage consuming (10 cases, 62.5\%) and smoker ( 9 cases, $60.0 \%$ ), and $35.3 \%$ (6 cases) showed overweight. The symptoms more frequently reported were: dysphagia (12 cases, $66.7 \%$ ), and weight loss (7 cases, 38.9\%).

Comorbidity was reported in $38.9 \%$ of the patients, and the principal diseases were Barrett's esophagus ( 2 cases, $11.1 \%$ ), caustic soda ingestion (one case, 5.6\%) and gastric ulcer ( 8 cases, $44.4 \%$ ). Treatment varied depending on the characteristic of each patient and tumor. The most frequent options were: transhiatal esophagectomy (6 cases, 33.3\%), transthoracic esophagectomy (4 cases, 22.2\%), and radiotherapy (4 cases, $22.2 \%$ ). Two patients (11.1\%) were also treated with chemotherapy (one of them also treated by surgery and three by radiotherapy).

Anatomical location showed $1(5.6 \%)$ case in superior esophageal area (20 to $25 \mathrm{~cm}$ from superior dental arcade, SDA), 8 (44.4\%) cases in mid esophagus (25 to $30 \mathrm{~cm}$ from SDA) and $9(50.0 \%$ ) in inferior esophagus (30 to $40 \mathrm{~cm}$ from SDA).

Time of follow up ranged from one to 71 months. There were four cases of recurrence $(23.5 \%)$, and free disease interval of $100 \%$ and $82.5 \%$, for 12 and 36 months, respectively (Table 2). The significant prognostic factors were age $(\mathrm{p}=0.009)$, epigastralgia $(\mathrm{p}=0.038)$ and chemotherapy $(\mathrm{p}$ $<0.001)$.

From 18 patients, $6(33.3 \%)$ died during the 36 months follow up, five of them between one to 31 months after diagnosis (1, 4, 5, 14 and 31 months, respectively), and one patient died for other causes than esophageal cancer. Second malignant tumor occurred in $5(27.8 \%)$ cases, one lung cancer $(20.0 \%)$, one prostate cancer $20.0 \%$, two head and neck cancer $(40.0 \%)$ and one non-melanoma skin cancer $(20.0 \%)$, but these tumors did not influence the survival rates in 36 months follow up. None of the patients who died before 36 months had second primary tumor.

Global survival rates probabilities were $76.7 \%$ and 64.4\% after 12 and 36 months follow up, respectively (Table 3).

\section{Discussion}


Table 1. Number and Percentage of Patients According to Socio-demographic and Clinical Characteristics, and Lifestyle

\begin{tabular}{|c|c|c|c|}
\hline Variable & Category & $\mathbf{n}$ & $\%$ \\
\hline \multirow[t]{2}{*}{ Gender } & Male & 15 & 83.3 \\
\hline & Female & 3 & 16.7 \\
\hline \multirow[t]{2}{*}{ Age } & $\leq 49$ years old & 4 & 22.2 \\
\hline & $\geq 50$ years old & 14 & 77.8 \\
\hline \multirow[t]{3}{*}{ State of origin } & Minas Gerais & 5 & 27.8 \\
\hline & Mato Grosso do Sul & 1 & 5.6 \\
\hline & Sao Paulo & 12 & 66.7 \\
\hline \multirow[t]{4}{*}{ Schooling } & Non & 5 & 27.8 \\
\hline & Basic incomplete & 11 & 61.1 \\
\hline & Basic complete & 1 & 5.6 \\
\hline & High school & 1 & 5.6 \\
\hline \multirow[t]{2}{*}{ Tabagism } & Never/ Former smoker & 9 & 60.0 \\
\hline & Current smoker & 6 & 40.0 \\
\hline \multirow[t]{2}{*}{ Etilism } & Never & 6 & 37.5 \\
\hline & Ever & 10 & 62.5 \\
\hline \multirow[t]{3}{*}{ Body Mass Index (BMI) } & $\leq 18.5$ & 5 & 29.4 \\
\hline & $18.5-25.9$ & 6 & 35.3 \\
\hline & $\geq 26.0$ & 6 & 35.3 \\
\hline \multirow[t]{2}{*}{ Comorbidity } & Absent & 11 & 61.1 \\
\hline & Present & 7 & 38.9 \\
\hline \multirow[t]{2}{*}{ Second primary tumor } & Yes & 5 & 27.8 \\
\hline & No & 13 & 72.2 \\
\hline \multirow[t]{2}{*}{ Histological type } & Squamous cell carcinoma & 16 & 88.9 \\
\hline & Adenocarcinoma & 2 & 11.1 \\
\hline \multirow[t]{2}{*}{ Stage (TNM) } & 0 & 3 & 16.7 \\
\hline & 1 & 15 & 83.3 \\
\hline \multirow[t]{7}{*}{ Therapeutics } & Radiotherapy & 4 & 22.2 \\
\hline & Surgery and radiotherapy & 1 & 5.6 \\
\hline & Surgery and chemotherapy & 1 & 5.6 \\
\hline & Radiotherapy and chemotherapy & 1 & 5.6 \\
\hline & Transthoracic esophagectomy & 4 & 22.2 \\
\hline & Transhiatal esophagectomy & 6 & 33.3 \\
\hline & Esophageal gastroplasty & 1 & 5.6 \\
\hline Total & & 18 & 100 \\
\hline
\end{tabular}

The results herein reported have shown similar socio-demographic characteristic to the Japanese $[14,15]$ and Korean data [16]. The small number of patients included in the casuistic reflects, in part, the recurrent difficulties to reach patients with incipient esophageal cancer. We investigated 16 years of casuistic and from 1,853 patients only $18(1.0 \%)$ have had early esophageal cancers.

This is very alarming because the vast majority of the patients have advanced esophageal cancer stage at the time of diagnosis, due to the lack of symptoms in the early stages [5]. For the 18 patients of this study, the symptoms (dyspha- gia, epigastralgia and loss of weight) differed from Dutch patients who predominantly presented gastroesophageal reflux disease (69\%), and dysphagia (9\%) and epigastralgia (19\%) in very small proportion in comparison to Brazilian patients [17]. Also, Dutch patients have showed 36 months of free disease interval in $88 \%$ of the patients, similar to data observed in our study [17].

Comparatively, the free disease interval in five years for Japanese patients was $93 \%$, slightly higher to the $82.5 \%$ observed Brazilian casuistic in three years [15]. Additionally, Japanese patients showed $7.2 \%$ of recurrence in five years 
Table 2. Free Disease Interval Rates Probabilities in Patients With Insipient Esophageal Cancer (Clinical Stage 0 and I - TNM) From Barretos Cancer Hospital, Diagnosed From 1996 To 2005

\begin{tabular}{|c|c|c|c|c|c|}
\hline \multirow{2}{*}{ Variable } & \multirow{2}{*}{ Category } & \multirow[t]{2}{*}{$\mathbf{n}$} & \multicolumn{2}{|c|}{ Free disease rates probabilities $(\%)$} & \multirow[t]{2}{*}{ p (Log-Rank) } \\
\hline & & & 12 months & 36 months & \\
\hline \multirow[t]{2}{*}{ Gender } & Male & 15 & 100.0 & 78.8 & 0.502 \\
\hline & Female & 3 & - & - & \\
\hline \multirow[t]{2}{*}{ Age } & $\leq 49$ years old & 4 & 100.0 & 33.3 & 0.009 \\
\hline & $\geq 50$ years old & 14 & - & - & \\
\hline \multirow[t]{3}{*}{ Schooling } & Never & 5 & - & - & 0.468 \\
\hline & Basic incomplete & 11 & 100.0 & 87.5 & \\
\hline & Basic complete/ High school & 2 & 100.0 & 50.0 & \\
\hline \multirow[t]{2}{*}{ Tabagism } & Never and/or former smoker & 6 & 100.0 & 80.0 & 0.744 \\
\hline & Current smoker & 9 & 100.0 & 75.0 & \\
\hline \multirow[t]{2}{*}{ Etilism } & Never & 6 & - & - & 0.371 \\
\hline & Ever & 10 & 100.0 & 80.0 & \\
\hline \multirow[t]{2}{*}{ Weight loss } & Yes & 7 & - & - & 0.445 \\
\hline & No & 11 & 100.0 & 77.8 & \\
\hline \multirow[t]{2}{*}{ Odinophagia } & Yes & 6 & - & - & 0.335 \\
\hline & No & 12 & 100.0 & 75.0 & \\
\hline \multirow[t]{2}{*}{ Dysphagia } & Yes & 12 & 100.0 & 68.6 & 0.192 \\
\hline & No & 6 & - & - & \\
\hline \multirow[t]{2}{*}{ Epigastralgia } & Yes & 6 & 100.0 & 50.0 & 0.038 \\
\hline & No & 12 & - & - & \\
\hline \multirow[t]{2}{*}{ Pyrosis } & Yes & 4 & - & - & 0.383 \\
\hline & No & 14 & 100.0 & 76.2 & \\
\hline \multirow[t]{2}{*}{ Body Mass Index (BMI) } & $\leq 18.5$ & 5 & - & & 0.445 \\
\hline & $>18.5$ & 12 & 100.0 & 77.8 & \\
\hline \multirow[t]{2}{*}{ Comorbidity } & Absent & 11 & - & - & 0.116 \\
\hline & Present & 7 & 100.0 & 62.5 & \\
\hline \multirow[t]{2}{*}{ Second primary tumor } & Yes & 5 & - & - & 0.383 \\
\hline & No & 13 & 100.0 & 76.2 & \\
\hline \multirow[t]{2}{*}{ Tumor size } & $\leq 2.0 \mathrm{~cm}$ & 6 & 100.0 & 80.0 & 0.886 \\
\hline & $>2.0 \mathrm{~cm}$ & 10 & 100.0 & 80.0 & \\
\hline \multirow[t]{2}{*}{ Histological type } & Squamous cell carcinoma & 16 & 100.0 & 90.0 & 0.247 \\
\hline & Adenocarcinoma & 2 & 100.0 & 50.0 & \\
\hline \multirow[t]{2}{*}{ Stage (TNM) } & 0 & 3 & - & - & 0.383 \\
\hline & 1 & 15 & 100.0 & 76.2 & \\
\hline \multirow[t]{2}{*}{ Surgery } & Yes & 13 & 100.0 & 87.5 & 0.351 \\
\hline & No & 5 & 100.0 & 66.7 & \\
\hline \multirow[t]{2}{*}{ Radiotherapy } & Yes & 6 & 100.0 & 66.7 & 0.351 \\
\hline & No & 12 & 100.0 & 87.5 & \\
\hline \multirow[t]{2}{*}{ Chemotherapy } & Yes & 2 & 100.0 & 0.0 & $<0.001$ \\
\hline & No & 16 & - & - & \\
\hline Total & & 18 & 100.0 & 82.5 & \\
\hline
\end{tabular}

of follow up [8], different from Brazilian casuistic which in five years revealed $22.2 \%$ in the same period. Interestingly Pech et al reported that the only parameter statistically inde- pendent to predict recurrence is the multifocal lesions, which we failed to demonstrate [12].

The overall results clearly demonstrated that survival 
Table 3. Global Survival Rates Probabilities in Patients With Insipient Esophageal Cancer (Clinical Stage 0 and I - TNM) From Barretos Cancer Hospital, Diagnosed From 1996 To 2005

\begin{tabular}{|c|c|c|c|c|c|}
\hline \multirow{2}{*}{ Variable } & \multirow{2}{*}{ Category } & \multirow{2}{*}{$\mathbf{n}$} & \multicolumn{2}{|c|}{ Global survival rates probabilities (\%) } & \multirow{2}{*}{ p (Log-Rank) } \\
\hline & & & 12 months & 36 months & \\
\hline \multirow[t]{2}{*}{ Gender } & Male & 15 & 73.3 & 59.3 & 0.302 \\
\hline & Female & 3 & - & - & \\
\hline \multirow[t]{2}{*}{ Age } & $\leq 49$ years old & 4 & 100.0 & 66.7 & 0.747 \\
\hline & $\geq 50$ years old & 14 & 71.4 & 64.3 & \\
\hline \multirow[t]{3}{*}{ Schooling } & Never & 5 & 53.3 & 53.3 & 0.628 \\
\hline & Basic incomplete & 11 & 81.8 & 72.7 & \\
\hline & Basic complete/ High school & 2 & 100.0 & 50.0 & \\
\hline \multirow[t]{2}{*}{ Tabagism } & Never and/or former smoker & 6 & 100.0 & 80.0 & 0.188 \\
\hline & Current smoker & 9 & 50.8 & 50.8 & \\
\hline \multirow[t]{2}{*}{ Etilism } & Never & 6 & 83.3 & 66.7 & 0.584 \\
\hline & Ever & 10 & 67.5 & 54.0 & \\
\hline \multirow[t]{2}{*}{ Weight loss } & Yes & 7 & 57.1 & 42.9 & 0.081 \\
\hline & No & 11 & 90.0 & 80.0 & \\
\hline \multirow[t]{2}{*}{ Odinophagia } & Yes & 6 & 83.3 & 66.7 & 0.869 \\
\hline & No & 12 & 73.3 & 64.2 & \\
\hline \multirow[t]{2}{*}{ Dysphagia } & Yes & 12 & 73.3 & 53.5 & 0.294 \\
\hline & No & 6 & 83.3 & 83.3 & \\
\hline \multirow[t]{2}{*}{ Epigastralgya } & Yes & 6 & 80.0 & 60.0 & 0.956 \\
\hline & No & 12 & 75.0 & 66.7 & \\
\hline \multirow[t]{2}{*}{ Pyrosis } & Yes & 4 & - & - & 0.191 \\
\hline & No & 14 & 71.4 & 56.3 & \\
\hline \multirow[t]{2}{*}{ Body Mass Index (BMI) } & $\leq 18.5$ & 5 & 60.0 & 60.0 & 0.443 \\
\hline & $>18.5$ & 12 & 90.9 & 72.7 & \\
\hline \multirow[t]{2}{*}{ Comorbidity } & Absent & 11 & 70.7 & 60.6 & 0.599 \\
\hline & Present & 7 & 85.7 & 68.6 & \\
\hline \multirow[t]{2}{*}{ Second primary tumor } & Yes & 5 & 60.0 & 60.0 & 0.596 \\
\hline & No & 13 & 83.3 & 65.6 & \\
\hline \multirow[t]{2}{*}{ Tumor size } & $\leq 2.0 \mathrm{~cm}$ & 6 & 83.3 & 83.3 & 0.315 \\
\hline & $>2.0 \mathrm{~cm}$ & 10 & 78.8 & 54.0 & \\
\hline \multirow[t]{2}{*}{ Histological type } & Squamous cell carcinoma & 16 & 73.7 & 67.0 & 0.858 \\
\hline & Adenocarcinoma & 2 & 100.0 & 50.0 & \\
\hline \multirow[t]{2}{*}{ Stage (TNM) } & 0 & 3 & - & - & 0.202 \\
\hline & 1 & 15 & 71.8 & 56.5 & \\
\hline \multirow[t]{2}{*}{ Surgery } & Yes & 13 & 75.0 & 65.6 & 0.757 \\
\hline & No & 5 & 80.0 & 60.0 & \\
\hline \multirow{2}{*}{ Radiotherapy } & Yes & 6 & 66.7 & 50.0 & 0.306 \\
\hline & No & 12 & 81.8 & 71.6 & \\
\hline \multirow[t]{2}{*}{ Chemotherapy } & Yes & 2 & 73.7 & 67.0 & 0.858 \\
\hline & No & 16 & 100.0 & 50.0 & \\
\hline Total & & 18 & 76.7 & 64.4 & \\
\hline
\end{tabular}

rates and free disease interval are not associated to the sociodemographic and clinical characteristics. The five years sur- vival rates for all clinical stages in Singapore showed 3\% and $6 \%$ for male and female, respectively [10] and relative sur- 
vival rates for Netherlands were $7 \%$ and $18 \%$, Italy $6 \%$ and $13 \%$, Slovakia Republic $7 \%$ and $16 \%$ and Denmark $2 \%$ and $9 \%$ [9]. These values reinforce the aggressiveness of esophageal cancer and endorse the necessity for early cancer detection and cancer prevention. The figures of global survival rates from patients with incipient tumor ratify this premise. German numbers showed survival rates of $83.4 \%$ for precancerous adenocarcinoma and $62.9 \%$ for invasive squamous cells carcinoma [18], and $77 \%$ after 5 years in USA [19]. Korea data showed a global survival rate of $84.3 \%$ [16], and Japan $67 \%$ for initial cancer stages (T1 and Tis) [14]. However, Japanese studies have also showed five years survival rates ranging from $73 \%$ to $80 \%[8,15]$; and for China a slight superior index of $86 \%$ was reported [20]. These numbers do not have a parallel in our study since we demonstrated worse survival rates along the patients follow up. This is a very disturbing observation because reflect, in part, a possible lack of preventive treatment or difficulties to access specialized medical care. Actually, the majority of the cases analyzed in this study showed an advanced stage of cancer, which certainly reduces the advantage of an efficient treatment. Even patients with initial stage of esophageal cancer have showed some homeostatic disorders since weight decrease of the patients was the most prevalent symptom reported.

Good prognosis parameters, such as age under 65 years old, female and tumor with size less than $5 \mathrm{~cm}$ did not correlate with our group of patients. On the other hand, wellestablished parameters of worse prognosis factors include loss of weight in Karnofsky scale [21, 22], which strongly corroborated our findings. Additionally, we observed that patients with squamous cell carcinoma have had a three years global survival rate superior than those with adenocarcinoma (67.0\% versus $50.0 \%$, respectively), inversely different from the findings reported by Stein et al [13].

Also, the present study did not corroborate previous reports where the type of treatment influenced the global survive rates. None of the treatment options used for our patients demonstrate any superior performance for this particular proposal. Surgical complications are believed to be one of the most important limitations for good treatment response [19]. Clearly, surgical treatment for initial stages demonstrated better survival rates [7]. Nonetheless, surgeries for initial stages are less invasive which diminish the post-surgical complication [18]. This is promising result corroborated by the results obtained by the endoscopic surgeries for superficial esophageal carcinomas [7, 8, 12, 23, 24].

In conclusion, the main characteristics of Brazilian patients with initial esophageal cancer were comparable to the other countries, including the rates of free disease interval. However, the global survival rates were importantly inferior to those observed elsewhere. Our results, however, should be taking in account very cautiously because of the small number of incipient esophageal carcinomas studied. Moreover, the discrepancies herein reported suggest that the problem is strongly associated to the advanced stage of disease at the moment of diagnosis, which significantly reduce the opportunities for better figures in terms of global survival rates.

\section{References}

1. Karim-Kos HE, de Vries E, Soerjomataram I, Lemmens V, Siesling S, Coebergh JW. Recent trends of cancer in Europe: a combined approach of incidence, survival and mortality for 17 cancer sites since the 1990s. Eur J Cancer 2008;44(10):1345-1389.

2. Jemal A, Siegel R, Ward E, Hao Y, Xu J, Murray T, Thun MJ. Cancer statistics, 2008. CA Cancer J Clin 2008;58(2):71-96.

3. Brasil Ministerio da Saude. Secretaria de Atencao à Saúde. Instituto Nacional do Cancer. Coordenacao de Prevencao e Vigilancia de Cancer. Estimativas 2008: Incidencia de cancer no Brasil. Rio de Janeiro: INCA; 2007. (Official publication of Brazilian Health's authorities).

4. Demeester SR. Epidemiology and biology of esophageal cancer. Gastrointest Cancer Res 2009;3(2 Suppl):S2-5.

5. Ojala K, Sorri M, Jokinen K, Kairaluoma M. Symptoms of carcinoma of the oesophagus. Med J Aust 1982;1(9):384-385.

6. Blot WJ. Esophageal cancer trends and risk factors. Semin Oncol 1994;21(4):403-410.

7. Fujita H, Sueyoshi S, Yamana H, Shinozaki K, Toh U, Tanaka Y, Mine T, et al. Optimum treatment strategy for superficial esophageal cancer: endoscopic mucosal resection versus radical esophagectomy. World J Surg 2001;25(4):424-431.

8. Ishihara R, Tanaka H, Iishi H, Takeuchi Y, Higashino K, Uedo N, Tatsuta M, et al. Long-term outcome of esophageal mucosal squamous cell carcinoma without lymphovascular involvement after endoscopic resection. Cancer 2008;112(10):2166-2172.

9. Faivre J, Forman D, Esteve J, Gatta G. Survival of patients with oesophageal and gastric cancers in Europe. Eur J Cancer 1998;34(14):2167-2175.

10. Chia KS, Du WB, Sankaranarayanan R, Sankila R, Seow A, Lee HP. Population-based cancer survival in Singapore, 1968 to 1992: an overview. Int J Cancer 2001;93(1):142-147.

11. Katada C, Muto M, Manabe T, Ohtsu A, Yoshida S. Local recurrence of squamous-cell carcinoma of the esophagus after EMR. Gastrointest Endosc 2005;61(2):219225.

12. Pech O, May A, Gossner L, Rabenstein T, Manner H, Huijsmans J, Vieth M, et al. Curative endoscopic therapy in patients with early esophageal squamous-cell carcinoma or high-grade intraepithelial neoplasia. Endos- 
copy 2007;39(1):30-35.

13. Stein HJ, Feith M, Bruecher BL, Naehrig J, Sarbia M, Siewert JR. Early esophageal cancer: pattern of lymphatic spread and prognostic factors for long-term survival after surgical resection. Ann Surg 2005;242(4):566-573; discussion 573-565.

14. Endo M, Yoshino K, Kawano T, Nagai K, Inoue $H$. Clinicopathologic analysis of lymph node metastasis in surgically resected superficial cancer of the thoracic esophagus. Dis Esophagus 2000;13(2):125-129.

15. Tachibana M, Hirahara N, Kinugasa S, Yoshimura H. Clinicopathologic features of superficial esophageal cancer: results of consecutive 100 patients. Ann Surg Oncol 2008;15(1):104-116.

16. Kim JH, Chung HS, Youn YH, Park SW, Song SY, Chung JB, Kim CB, et al. Treatment outcomes of 70 cases of early esophageal carcinoma: 12 years of experience. Dis Esophagus 2007;20(4):297-300.

17. van Sandick JW, van Lanschot JJ, ten Kate FJ, Offerhaus GJ, Fockens P, Tytgat GN, Obertop H. Pathology of early invasive adenocarcinoma of the esophagus or esophagogastric junction: implications for therapeutic decision making. Cancer 2000;88(11):2429-2437.

18. Ikeguchi M, Maeta M, Kaibara N. Limited operation for patients with T1 esophageal cancer. Langenbecks Arch Surg 2000;385(7):454-458.

19. Rice TW, Blackstone EH, Goldblum JR, DeCamp MM,
Murthy SC, Falk GW, Ormsby AH, et al. Superficial adenocarcinoma of the esophagus. J Thorac Cardiovasc Surg 2001;122(6):1077-1090.

20. Wang GQ, Jiao GG, Chang FB, Fang WH, Song JX, $\mathrm{Lu} \mathrm{N}$, Lin DM, et al. Long-term results of operation for 420 patients with early squamous cell esophageal carcinoma discovered by screening. Ann Thorac Surg 2004;77(5):1740-1744.

21. Roth JA, Pass HI, Flanagan MM, Graeber GM, Rosenberg JC, Steinberg S. Randomized clinical trial of preoperative and postoperative adjuvant chemotherapy with cisplatin, vindesine, and bleomycin for carcinoma of the esophagus. J Thorac Cardiovasc Surg 1988;96(2):242248.

22. Swisher SG, Holmes EC, Hunt KK, Doty JE, Zinner MJ, McFadden DW. The role of neoadjuvant therapy in surgically resectable esophageal cancer. Arch Surg 1996;131(8):819-824; discussion 824-815.

23. Ell C, May A, Pech O, Gossner L, Guenter E, Behrens A, Nachbar L, et al. Curative endoscopic resection of early esophageal adenocarcinomas (Barrett's cancer). Gastrointest Endosc 2007;65(1):3-10.

24. Peters FP, Kara MA, Rosmolen WD, Aalders MC, Ten Kate FJ, Bultje BC, Krishnadath KK, et al. Endoscopic treatment of high-grade dysplasia and early stage cancer in Barrett's esophagus. Gastrointest Endosc 2005;61(4):506-514. 